\title{
El Estado Penal Neoliberal
}

\author{
Sebastian Rodrigo Ghersi
}

\section{SUMÁRIO}

I- Introducción.

II - Cuáles son los fundamentos y las consecuencias de este modelo neoliberal?

II - La intervención del Estado para que y por qué?

IV-El revivir de una metodología que atiende a las consecuencias y olvida las causas.

$V$ - Reflexiones finales.

\section{I - INTRODUCCIÓN}

$$
\text { 17, }
$$

orden neoliberal, que en realidad es más viejo que la historia misma, lleva a la sociedad de hoy a plantear temas que parecían hasta hace poco descartados y olvidados.

Es el caso de la pena de muerte, la mano dura, la encarcelación masiva, la idea de delito "malo" y la del delincuente como ente diferente del resto de la sociedad.
El mayor problema es que gran parte de la sociedad, no ve como causas de la criminalidad masiva, ni de la violencia exacerbada, la desocupación y el hambre generada por este mismo modelo. Consecuencia de esto, los discursos represivos y facilistas, que nos hacen recordar a otras épocas difíciles de nuestro país $y$ del mundo, convocan a multitudes prometiendo construcción de cárceles y mano dura como soluciones a un problema complejo que no puede resolverse por esos medios.

El modelo neoconservador que ha demostrado producir las mismas consecuencias en todo lugar que se aplicó, de esta forma produce, por un lado, multitudes de desocupados "sobrantes" del sistema y por otro, genera los mecanismos represivos (aunque nunca parecen suficientes) para "sacar del medio" a las clases excluidas de los cálculos de la economía y reforzar así el control social que intenta mantener el statu quo societario.

En similar sentido se expresa el francés, Loïc Wacquant que plantea, que éste (el Estado neoliberal) "gobierna de inseguridad social" se apoya, por un lado, en la disciplina del mercado laboral descalificado y desregulado y por el otro, en un aparato invasor y omnipresente ${ }^{1}$.

1 Arnedo, Fernando Javier, comentando "las cárceles de la miseria" de Loïc Wacquant, Rev. Foro Año 1 N1 1. Bs. As. Mayo de 2000, pag 70 
II- CUÁLES SON LOS FUNDAMENTOS $Y$ LAS CONSECUENCIAS DE ESTE MODELO NEOLIBERAL

Esta concepción parte del análisis numérico de la sociedad y no de uno personalizado, es decir que no importa que el cuerpo societario este constituido por personas, que sólo son observadas como cifras de cálculo.

Los defensores de este sistema, basando su análisis, aunque sin mencionarlo, en la consideración de la sociedad como un orden social justo, como la realización del llamado sueño americano, donde el delincuente aparece como un sujeto reticente al esfuerzo y al trabajo, y es caracterizado como estereotipo de maldad, en contraposición con el ciudadano "digno" que está donde está, gracias a su esfuerzo inconmensurable y no debido a facilidades otorgadas por su lugar de nacimiento.

En 1956, un defensor acérrimo de la pena de muerte decía: "Advierto desde ahora que de ninguna manera soy amigo de la violencia; sino sólo de la justicia, porque todo lo que traspasa la justicia es malo y el mal no tiene derecho a existir en ninguna de sus manifestaciones."

Esta característica infrahumana con la que define al delincuente hace que la sociedad influenciada por este pensamiento, se preocupe menos aún de la situación carcelaria. Si la vida del delincuente en libertad no importa, menos importará su situación en la cárcel. De esta forma la pena del delincuente se multi plica, ya no sólo significará la pérdida de la libertad locomotriz, significará también vivir en condiciones inhumanas, peligro de sufrir violaciones y maltrato, contagio de HIV, Hepatitis o tuberculosis, etc.

En muchos casos significará la muerte, para quienes mueren dentro de la prisión, para quienes salen contagiados de enfermedades, $e$ quiesos salen contagiados de enfermedar, su condena, son liberados en un mundo ( $y$ sobretodo en un país) donde se le negará trabajo, porque se presumirá su delincuencia nata porque antela enorme oferta laboral, difícil será que se tome como empleado a un ex-presidiario un excombatiente de Malvinas (con presunción de locura), o un enfermo infeccioso, peor aún si reúne las tres condiciones.

Entonces, cualquier delito cometido significara el fin de cualquier esperanza. Poco importara para mucha gente que nuestras cárceles tengan un clientelismo reiterado en clases afectadas con una economía de marginación y hambre, sin salida laboral ni oportunidad alguna, ni tampoco importará la estigmatización de nuestro sistema policial y judicial que persigue con distinto ahínco a unos y otros.

Sin querer de ningún modo justificar esta situación, también podemos hablar de la situación de los preso preventivos, que sin importar si son culpables o inocentes sufren similares consecuencias cuando reingresan a la sociedad.

El modelo neoliberal de la defensa social, termina siendo, una prerrogativa de sangre 0 de lugar de nacimiento.

\section{III-LA INTERVENCIÓN DEL ESTADO} PARA QUÉ Y POR QUÉ?

Es de destacar, la contradicción que hace notar Waccquant ${ }^{3}$, que tiene que ver con que los que hoy glorifican este Estado penal, son los mismos que exigen menos estado en materia

2 Nuñez, David, La pena de muerte frente a la iglesia y al estado, Bs.As., 1956, ED. ABECE, pag. 10. 3 Arnedo, Fernando Javier, comentando "las cárceles de la miseria" de Loic Wacquant, Rev. Foro Año 1 NI 1. Bs. As. Mayo de 2000, pag. 70

económica y social y lograron imponer esta "dictadura de las grandes empresas".

Esto desenmascara el fetiche neoliberal y muestra que su verdadera intención, no es reducir el Estado, sino reducirlo sólo en la parte conveniente para determinada clase, produciendo, no un Estado que no participa, sino un Estado parcializado.

El paso del modelo del Estado Keynesiano, como dice este autor, (yo diría Keynesiano-Bismarkiano) al modelo del Estado Darwinista, es un invento de la escuela de Manhattan de Estados Unidos, y esparcido por todo el mundo. Esto queda confirmado si observamos las cifras extraídas de ese país. ${ }^{4}$

En aquel país sólo 13 de sus 40 estados no tiene pena de muerte. Desde la reinstauración de la pena de muerte en 1976, no casualmente en la misma época del cambio de modelo, se han ejecutado (hasta el 1 de julio del 2000, 625 personas en los que están incluidos 34 personas con retraso mental. El porcentaje de blancos ejecutados es de $56 \%$, mientras que las personas de color es de $35 \%$, cifra nada concurrente con los equivalentes de población total, donde la gente de color representa alrededor del $15 \%$. También afirma el estudio consultado que 23 personas ejecutadas desde 1900 eran inocentes. Los métodos de ejecución que se siguen usando en este momento son 5: la inyección letal, la electrocución, el gas letal, el escuadrón de fusilamiento y el colgamiento (estos últimos métodos compartidos sólo por 3 Estados).

Lo peor de todo quizá es que en la opinión pública norteamericana aproximadamente el $66 \%$ de la población está de acuerdo con la pena de muerte. Esto se ve confirmado

4 Death Penalaty Information Center, http:/www.deathpenaltyinfo.org/DRUSA-SupCourt.Html ${ }_{5}$ Diario Metro, 3 de noviembre de 2000, pag. 4. con las últimas elecciones presidenciales de este país, en las cuales la mitad de los votantes dio su voto al gobernador de Texas, que precisamente es el Estado con record de ejecuciones en el país del norte, con 34 personas hasta la fecha ${ }^{5}$, entre los cuales 4 fueron ejecutados a pesar de la completa evidencia de su inocencia Ya no puede endosársele la culpa a algún dictador sin consenso, hoy es la gente quien pide por la muerte.

Cabe aclarar que aún estando en desacuerdo con el modelo norteamericano, debo decir que la situación es mucho peor en nuestro país y en general en la de todos los países latinoamericanos (salvo por la pena de muerte), que somos importadores de las peores cosas del modelo, como las ideas de tolerancia cero, mano dura, muerte a los delincuentes, etc. sin que se introduzcan los beneficios que tienen que ver con la protección de la industria nacional, no en un sentido xenófobo, sino en el sentido de protección del trabajo, el salario y el consumo

En otro aspecto y con el mismo sentido podemos afirmar que lo nocivo no con los trabajadores extranjeros que migran por cuestiones de necesidad (mediante los cuales los países se hacen grandes), sino los grandes monopolios extranjeros que buscan el máximo beneficio al menor costo, sin importar el factor humano, ni la destrucción de las economía regionales.

Tampoco se copian los mecanismos de contención necesarios para mantener bienestar social, refiriéndome con esto, no sólo a la seguridad social, sino también a la educación, la salud, la cultura y el esparcimiento, indispensables para la salud mental y fisica y

Revista da Faculdade de Direito da UFRGS, v. 19, Março/200 
para producir una permeabilidad social que destruya el establecimiento de clases parasitarias y la perpetuación de la riqueza.

Las cifras proyectadas por el ILANUD ${ }^{6}$, no dicen que en nuestra América Latina las tasas penitenciarias han crecido aceleradamente y de manera muy pronunciada a partir de 1992 (tiempos del comienzo de la aplicación del nuevo modelo), comprobándose en la mayoría de ellos sobrepoblación carcelaria.

El aumento tiene relación con el mayor uso de la pena de prisión, contradiciéndose as con el erróneo concepto de que los sistemas de justicia penal actúan de manera excesivamente benévola, encerrando pocas personas. Tampoco este aumento de la densidad poblacional carcelaria tiene que ver con el aumento demográfico de la población general. Basta ver que en nuestro país las personas presas pasaron de 21.016 en 1992, a 38.604 en 1999, de las cuales sólo un $10 \%$ del aumento pertenece al aumento demográfico (1.800) y un $90 \%$ al mayor uso de la prisión (15.788).

Estaremos en la antesala de otra importación que tiene que ver con el negocio de la privatización de las cárceles, que merecen un extenso comentario, que excede este trabajo y que bien trata Chiristie ${ }^{7}$, y que hace por ejemplo que California gaste 90 millones de dólares anuales en la pena de muerte, más que el costo ordinario del sistema de justicia, y que Florida halla gastado un total de 57 millones de dólares de 1973 a 1988 para 18 ejecuciones, o sea un promedio de 3,2 millones por cad ejecución, costo que se reduce a 2,3 millones en Texas (quizás tenga que ver con un precio mayorista), que equivale a casi 3 veces el costa de encarcelar a alguien en una celda sencilla a nivel más alto de seguridad por 40 años ${ }^{8}$ ?

IV-EL REVIVIR DE UNA METODO LOGÍA QUE ATIENDE A LAS CONSECUENCIAS Y OLVIDA LAS CAUSAS

Dice Chiristie ${ }^{9}$, que Estados Unidos, por sus criminólogos prestigiosos, cuidadosos con la normas cientificas, y porque sus normas pasan a ser nuestras normas y sus soluciones se copian en el extranjero, le hace recordar a la Alemania de los años 20 en adelante, que era aparentemente un país de cultura, conocimientos de ciencia, pensamientos racionales y corazones románticos, que fue modelo importante, quizás por demasiado tiempo. Creo que desgraciadamente esto es cierto y que sobre todo en los países con menor grado de desarrollo donde el modelo se recrudece.

El modelo Hegeliano ha tendido a reproducirse. Estamos más cerca que antes en el proyecto de Hegel, en el cual existía una de Kant) y que producía que la evolución le llegara a algunos y a otro no. En estos últimos el espíritu no se posaba y no llegaban a ser hombres libres.

Este modelo que intentaba proteger a la burguesía nórdica alemana del avance de las masas trabajadoras para las cuales los ideales de la revolución francesa no habían sido pensados, dividía en dos el mundo: el de los libres dominado por el contrato social y el de los no moral universal que evolucionaba (a diferencia

6 Elias, Carranza, "Las prisiones en América Latina”, Rev. Foro Año 1 N1 1. Bs. As. Mayo de 2000, pag. 14 yss. Chiristie, Nils. La industria del control del delito. Ed. Editores. Del Puerto. Bs. As. 1993

s Death Penalaty. Information Center, http://www.deathpenaltyinfo.org/DRUSA,Sup Court.Html 9 Christie, Nils. La industria del control del delito, pag. 87.

Revista da Faculdade de Direito da UFRGS, v. 19, Março/200 evolucionados, a los que sólo podían aplicárseles medidas de seguridad con la excusa de la defensa social.

Estas ideas que dejaron sembrado e camino para el régimen nazi, y que parecían lejanas, parecen hoy comunes. En nuestro paí la idea de la aplicación de la medida de seguridad con carácter general y permanente, esta a la orden del día. Hasta hace poco los extremistas que predicaban la eliminación del 2 por 1, para evitar la liberación masiva de los "delincuentes" eran la excepción, hoy parecen ser la regla, acompañados por el discurso de los medios de comunicación.

Olvidando por ejemplo que la culpa por la tardanza del juzgamiento es del Estado y no del imputado.

\section{V - REFLEXIONES FINALES}

Hemos de rogar porque este panoram sea solamente un planteo paranoico de uno pocos, pero mientras tanto debemos trabajar (en forma pacífica) para que las consecuencias no deseadas en este trabajo no se produzcan.

El Estado debe producir políticas sociales para todos los ciudadanos, especialmente para los jóvenes que en muchos casos provienen de un ambiente producto de la desunión, sin contacto con el afecto, cariño y ternura 10 medidas de carácter socioeconómico que logren el desarrollo de las regiones abandonadas, crear nuevas fuentes de trabajo, y de seguridad social.

Las políticas únicamente penales no sirven de nada, debe buscarse políticas integrales, no sólo penitenciarias, ni tampoco sólo policiales y funda, introducir formas no penales de resolución de conflictos.

También debe aclararse que es posible que el sistema ande bien, si se toman en cuenta sus fines históricos, y que seamos nosotros quienes lo queramos desnaturalizar.

El Estado nace como un método de control social y como dice Chiristie ${ }^{11}$ la sociedad industrial se genera a partir de la revolución mercantil y es sincrónico el surgiendo del sistema penal que conocemos, y que nace racista. Asi mismo, las "manos vacías" son un problema desde la primera etapa del proceso de industrialización, ya que se considera que causan por lo menos 2 ti pos de consecuencias: por un lado pueden provocar disturbios, y por el otro a contradicción que existe entre el estilo de vida forzado del desempleo y la moral oficial de la laboriosidad.

En esta concepción calculadora que crea el modelo, el sistema funciona como una máquina cuasi perfecta que crea los excluidos, genera los mecanismos punitivos para mantenerlos fuera de la sociedad y por otro lado, mantiene un sistema financiero de múltiples dimensiones, como lo es el control del delito. A esto debe sumársele (para demostrar que no es una teoría conspirativa), la ayuda irresponsable de sus partici pantes. Para que esto se entienda debe exportarse el esquema que Tolstoi ${ }^{12}$ utilizaba para explicar la barbarie de la guerra. El decía que la gran cantidad de muertes se producen, entre otras cosas. por el esquema piramidal en que el ejército está organizado, de tal forma que la acción sea inversamente pro-

10 Raminez Vela. Wilder. Sociedad y pena de muerte. Pag. 94. Ed. San Marcos. Lima. 1990

II Chiristie, Nils. La industria del control del delito, pag. 14. Ed. Editores. Del Puerto. Bs. As. 1993.

${ }^{2}$ Tolstoi, León. Guerra y paz, pag. 962 y ss. Grandes Clásicos. Tomo II. Ed. Aguilar. México 1991. 
porcional (no son palabras de Tolstoi) a la responsabilidad, lo que produce que el que da las ordenes no sea el que tiene que matar y por otro lado, que el que mata no se sienta responsable por la acción realizada. De igual manera nuestro sistema penal esta pensado para lograr iguales resultados.

El juez condena a una persona a una vida de miserias, y no asume su responsabilidad escuzándose en la existencia de la ley omni potente, el policía la cumple sin sentirse responsable porque no es quien tomó la decisión, sino sólo quien la hizo cumplir, el legislado que es quien dicta la ley, no será el que tiene que llevar al condenado a su celda, y de esta forma, indefinidamente. Así, ante este modelo, quienes no lo compartimos tenemos como opción cambiar su objetivo histórico desterrarlo. ${ }^{13}$

l3 Consult. Messer, Augusto. La flosofia modema de Kanty Hegel. Ed. Espasa - Calpe Argentina S.A. Buenos Aires. 1939; Marcuse, Herbert, Razón y revolución, Hegel y el surgimiento de la teoría social, ED. ALIANZA Madrid, 1971;-Nuñez, David, La pena de muerte frente a la Iglesia y al Estado, ED. ABECE, Bs. As, 1956 Ramirez Vela, Wilder, Sociedad y pena de muerte, EDITORLAL SANMARCOS, Lima, 1990 "Ejecutaron a un asesino arrepentido", Publimetro, Año 1, Nro. 19, 19 de noviembre de 2000.

\title{
EMENTA: "Doação Inoficiosa Art. 1.176 do CC - Querela Inofficiosa e Donationis . Requisitos"
}

\author{
Carlos Thompson Flores
}

Ministro aposentado e ex-Presidente do Supremo Tribunal Federal.

Obs.:

O presente parecer foi acolhido pelo STF quando do julgamento do $\mathrm{RE}_{\mathrm{n}} \mathrm{o}$ 97.060-RJ, rel. Min. Néri da Silveira, in RTJ 113/1.163.

\section{PARECER}

Encaminhou-me o eminente Professor Haroldo Valladão consulta sobre a possibilidade de dar parecer jurídico a respeito do recurso extraordiário interposto por sua cunhada Celeste Teixeira Valladão, casada, desde 11-3-1981, com seu irmão Alfredo Teixeira Valladão, Embaixador do Brasil na República Oriental do Uruguai, na ação ordinária que the movem Bruno e seu irmão Marcos Castrioto de Azambuja, recurso esse ora em tramitação perante o Egrégio Supremo Tribunal Federal.

Para o fim solicitado, passou-me às mão numerosas peças xerocopiadas, extraídas todas dos respectivos autos.

Proporcionaram elas detido e minucioso exame da controvérsia, findo o qual, conclu assistir razão à recorrente, pelo bom direito po ela sustentado, o qual lhe vem sendo negado.
Dispus-me, por isso, e só por isso, a emitir o presente parecer, no qual vou ater-me, tal como foi propugnado, ao âmbito do extraordinário em questão.

I - DO PROCEDIMENTO JUDICIAL E SEU DESFECHO

1. Em 14-5-1974, ajuizaram os autores Bruno e Marcos Castrioto de Azambuja, perante a $3^{a}$ Vara de Órfãos e Sucessões da comarca do Rio de Janeiro (RJ), contra a consulente Celeste, cujo sobrenome era, ao tempo, Pereira Malburg, ação ordinária, na qual, sucessivamente, pediram, usando da expressão confiam (11. 18),verbis:

“a) serão julgadas nulas de pleno direito, tendo em vista o disposto no art. 1.168 do Cód. Civil, as doaçoes, aqui indicadas, do BRIGADEIRO DARIO CAVALCANTI DE $A Z A M B U J A$, à ré; 